\title{
Dielectric and Thermal Studies of Copper Doped Magnesium Hydrogen Maleate Hexahydrate Single Crystals
}

\author{
B. Rajagopal ${ }^{1}$, A.V. Sarma ${ }^{2}$ and M.V. Ramana $^{3}$ \\ ${ }^{1}$ Department of Physics, Kavitha Degree College, Khammam, 507002 A.P., India \\ ${ }^{2}$ Department of Physics, Andhra University, Waltair, A.P., India \\ ${ }^{3}$ Department of Physics, SR\&BGNR degree College, Khammam, 507002 A.P., India \\ ${ }^{1}$ Corresponding author: rajagopal.bulusu@gmail.com
}

\begin{abstract}
The dielectric and thermal analysis of copper doped Magnesium Hydrogen Maleate Hexahydrate single crystals are studied for the first time. The dielectric constant, loss tangent, a.c. conductivity and a.c. activation energy were measured with variation of frequency in the range $50 \mathrm{~Hz}$ to $1 \mathrm{MHz}$. Dielectric studies reveal that the present crystal under investigation show good optical quality. The melting point and final compound after decomposition were determined using the DTA/TG analysis.
\end{abstract}

Keywords: Dielectric constant, loss tangent, TG, DTA

\section{INTRODUCTION}

The maleates are of practical importance because of their use as coatings with specific properties, efficient catalysts and are also of medicinal significance. Dielectric characteristics of organo-metallic crystals are of increasing importance as the field of solid state electronics continues to expand rapidly. For these applications the properties of most concern are the dielectric constant, loss tangent and a.c. conductivity. New devices and applications are continually increasing the frequency range and the range of environmental conditions, particularly temperature, that are of practical interest. The frequency dependent conductivity and dielectric constant provide important information on the ionic or electronic transport mechanism. It gives an insight into the structure of the materials since the localised electronic states within the material are created due to the presence of disorder in the atomic configuration and/or the composition. The structure of MHMH crystal was studied by various investigators [1,2]. Recently the synthesis and crystal structures on alkali metal maleates were studied [3]. The thermal decomposition of the complexes formed between manganese, cobalt, 
nickel, copper and zinc with maleic acid was studied using thermo-gravimetry TG and differential thermal analysis DTA [4]. Thermal analysis of transition metal carboxylates [5] has been subject of recent interest due to technological importance. The final thermolysis products (metal oxides) find extensive applications as catalysts, ceramic colorants, photoconductors, etc. The present investigation was focussed on the dielectric studies and thermal analysis of copper doped magnesium hydrogen maleate hexahydrate single crystals.

\section{MATERIALS AND METHODS}

Copper doped magnesium hydrogen maleate hexahydrate (hereafter $\mathrm{Cu}^{2+}: \mathrm{MHMH}$ ) single crystal were grown from the aqueous solution containing magnesium carbonate and maleic acid by slow evaporation method at room temperature. $\mathrm{Cu}^{2+}$ ions were introduced to an extent of $0.1 \mathrm{~mol} \%$, by the addition of solution of copper sulphate, using AnalaR grade reagents. Good quality $\mathrm{Cu}^{2+}: \mathrm{MHMH}$ crystals were grown from aqueous solution within a period of two weeks. The platy crystals grown were electroded with silver paste for electrical contact to study the a.c. electrical characteristics using Multi-frequency Hioki 3532-50 LCR Hi-Tester. In order to know the thermal behaviour, the $\mathrm{Cu}^{2+}$ :MHMH crystals was subjected to thermogravimetric analysis. The thermo-gravimetric analysis (TGA) and differential thermal analysis (DTA) were carried out using Netzsch STA 409 C/CD thermal analyzer at a heating rate of $10{ }^{\circ} \mathrm{C} \mathrm{min}^{-1}$ in the nitrogen atmosphere to determine the thermal stability of the compound. The crucible used was of alumina $\left(\mathrm{Al}_{2} \mathrm{O}_{3}\right)$, which served as a reference for the sample.

\section{RESULTS AND DISCUSSION}

\subsection{Dielectric Studies}

The dielectric constant $\varepsilon^{\prime}$ of $\mathrm{Cu}^{2+}$ :MHMH single crystal at different temperatures $308 \mathrm{~K}$, $323 \mathrm{~K}, 343 \mathrm{~K}, 363 \mathrm{~K}$ and $383 \mathrm{~K}$ with frequency range $50 \mathrm{~Hz}$ to $1 \mathrm{MHz}$ was presented in Figure 1. It was evident from the Figure 1 that the dielectric constant decreases with increase in frequency [6-10]. Also, the frequency dependence of dielectric constant $\varepsilon^{\prime}$ at different temperatures showed that at high frequencies the dielectric constant values were almost independent of temperature but as the frequency decreases the dielectric constant was more temperature dependent. The dielectric constant of the sample was more dispersive below $1 \mathrm{kHz}$ while decreases from $10 \mathrm{kHz}$. The high dielectric constant in the lower frequency region of the sample under investigation can be assigned to the presence of interfacial i.e., space charge polarization mechanism [11] and the low value of dielectric constant at higher frequencies may be due to the loss of significance of space charge polarisation gradually. The increase in dielectric constant with increasing temperature can be attributed to space charge polarisation near the grain boundary interfaces which depends on purity and perfection of the sample. It was evident from the Figure 2 that the loss tangent has high values at low frequencies and decreases with increasing frequency. The variation of loss tangent with frequency can be assigned to the dipole alignment when the field is applied. At low 
frequencies the dipoles can easily switch alignment with the changing field. As the frequency increases the dipoles are less able to rotate and maintain phase with the applied field, thus they reduce their contribution to the polarization field. The low loss tangent at high frequency is generally expected in the samples with good optical quality [12,13]. The loss tangent is strongly frequency dependent similar to that in L-Valine single crystal [14].

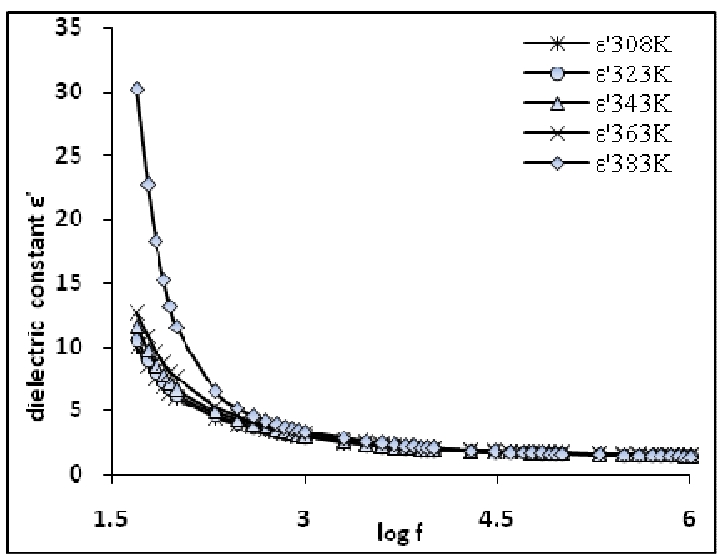

Figure 1. Dielectric constant versus $\log \mathrm{f}$

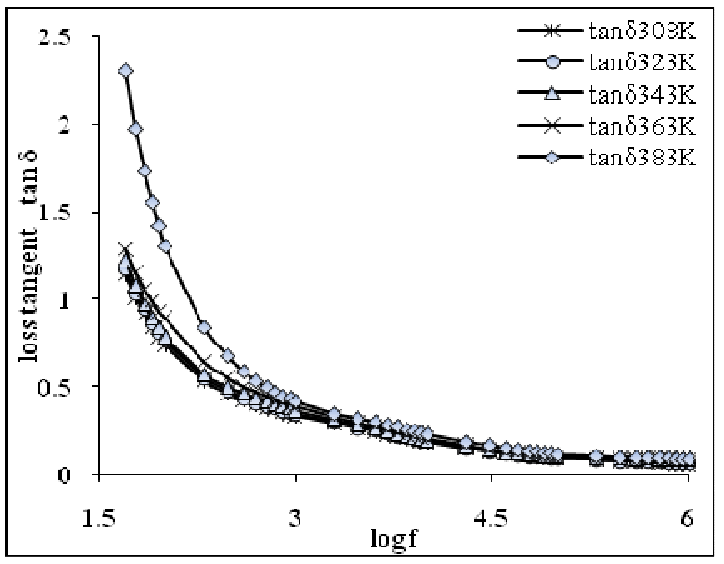

Figure 2. Loss tangent versus $\log \mathrm{f}$

It is observed from the Figure 3 that the a.c. conductivity has low values at lower frequencies and increases with increase in frequency and obeyed the empirical law

$$
\sigma(\omega) \alpha \omega^{\mathrm{n}}
$$

where " $\omega$ " is the angular frequency and the value of " $n$ " is frequency exponent depends on the temperature and frequency. The increase in a.c. conductivity could be due to the reduction in the space charge polarization. At low frequencies the a.c conductivity can be assigned to the trapping of some carriers at defect sites in the crystal. But at intermediate frequencies, it depends progressively of the frequency. At high frequencies, the a.c. conductivity is almost proportional to the frequency [15]. The behaviour of $\log \left(\sigma_{\mathrm{ac}}\right)$ against $1000 / \mathrm{T}$, at constant frequencies, was presented for the $\mathrm{Cu}^{2+}: \mathrm{MHMH}$ crystal in Figure 4. The activation energy of conduction " $\Delta \mathrm{E}$ " is calculated at different frequencies from the slopes of plot $\log \left(\sigma_{\mathrm{ac}}\right)$ against $1000 / \mathrm{T}$. It is observed that the slopes are decreasing with increasing temperature. The activation energy is $1.39 \mathrm{eV}$ for $100 \mathrm{~Hz}$ frequency at $363 \mathrm{~K}$ to $383 \mathrm{~K}$ temperatures. 


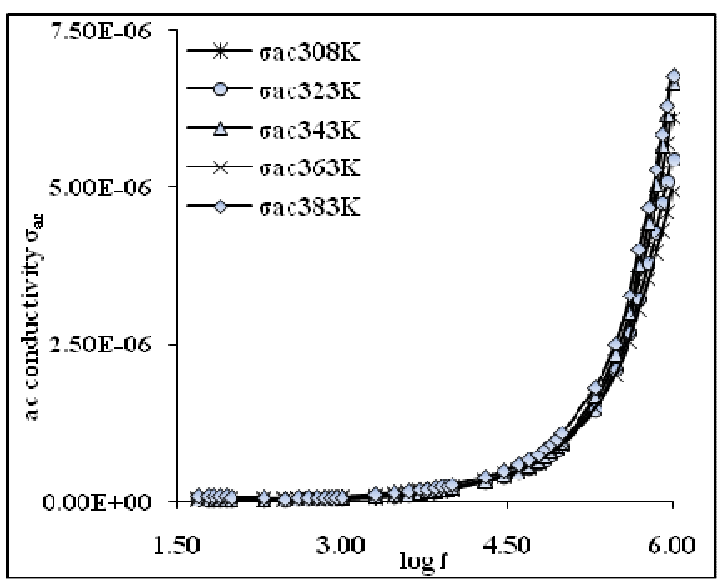

Figure 3. a.c. conductivity versus $\log f$

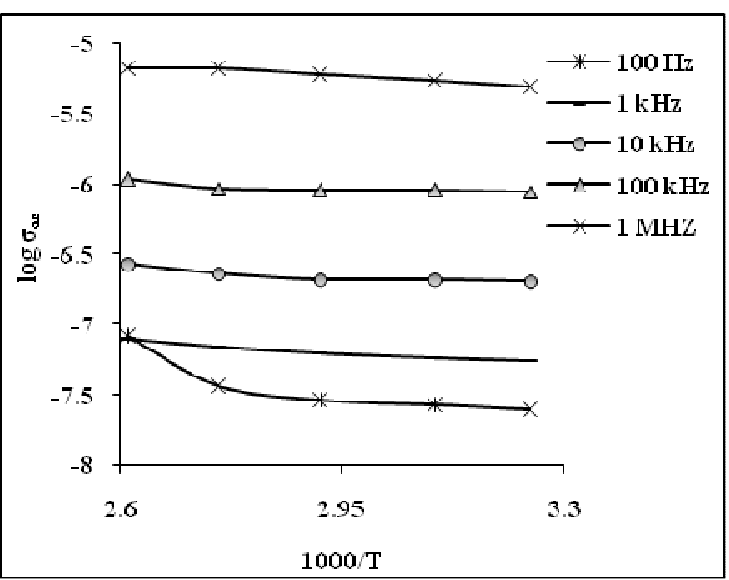

Figure 4. $\log \sigma_{\mathrm{ac}}$ versus 1000/T

\subsection{Thermal Studies}

Figure 5 depicts the TGA and DTA profile for $\mathrm{Cu}^{2+}: \mathrm{MHMH}$ crystal. The thermo gravimetric analysis of the present sample was carried out between $296 \mathrm{~K}$ and $1673 \mathrm{~K}$ in nitrogen atmosphere. An endothermic peak at $413.8 \mathrm{~K}$ can be attributed to the melting point of the sample [16]. The sample starts loosing water at $376.4 \mathrm{~K}$.

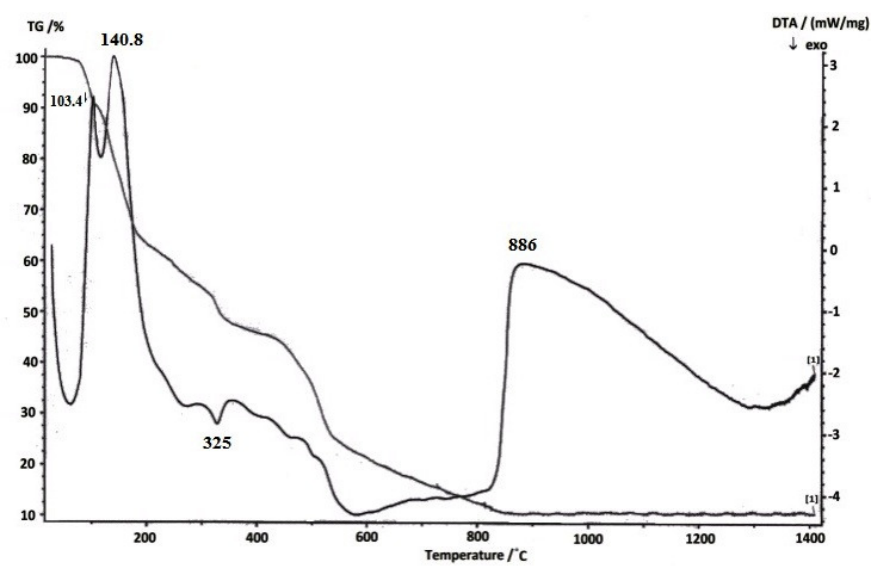

Figure 5. TG/DTA of $\mathrm{Cu}^{2+}:$ MHMH crystal

An exothermic peak was observed at 598K. Further, heating above melting point results in the formation of volatile substances $\mathrm{CO}$ and $\mathrm{CO}_{2}$ and rest of water molecule. The TG/DTA trace shows origin of major weight loss immediately after loss of water of crystallization. Therefore loss of water of crystallization, melting point and decomposition are expected to occur in sequential manner. Prolonged heating upto $1159 \mathrm{~K}$ does not produce any significant endothermic or exothermic peaks in TG/DTA curves. The loss of weight on heating the 
sample started almost in a continuous manner attaining constancy in weight at different temperatures.

\section{CONCLUSIONS}

Dielectric studies revealed that the sample under investigation possesses good optical quality. The melting point of the sample from DTA curve is close to that determined using capillary method. It is evident from the TGA that the final product of the sample after decomposition at $1159 \mathrm{~K}$ leaves a residue $\mathrm{MgO}$ whose molecular weight is approximately equal to its theoretical calculated value.

\section{REFERENCES}

1. M.P. Gupta, C. Van Alsenoy and A.T.H. Lenstra, 1984, "Magnesium bis(hydrogen maleate) hexahydrate", Acta Crystallogr, C40, pp 1521-1526.

2. F. Vanhouteghem, A.T.H. Lenstra and P. Schweiss, 1987, "Magnesium bis(hydrogen maleate) hexahydrate studied by elastic neutron diffraction and ab initio calculations", Acta Crystallogr, B43, pp 523-528.

3. Michel Fleck and 1. Bohaty, 2009a, "Crystal Structures and an Overview of Alkali Metal Maleates”, Zeitschrift Für Natur for Schung, Graphical abstracts Syntheses, 64B, No 5, pp 517-524.

4. J.R. Allan, G.M. Baillie, J.G. Bonner, D.L. Gerrard and S. Hoey, 1989, "Thermal studies on maleic acid compounds of manganese(II), cobalt(II), nickel(II), copper(II) and zinc(II)", Thermochim Acta, 143, pp 283-288.

5. B. S. Randhawa and K. Gandotra, 2006, "A Comparative study on the thermal decomposition of some transition metal carboxylates", J Thermal Analysis and Calorimetry, Vol 85, No 2, pp 417-424.

6. T. Uma Devi, N. Lawrence, R. Ramesh Babu, K. Ramamurthi and G. Bhagavannarayana, 2009b, "Structural, Electrical and Optical Characterization Studies on Glycine Picrate Single Crystal, A Third Order Nonlinear Optical Material”, J Minerals \& Materials Characterization \& Engineering, Vol 8, No 10, pp 755-763.

7. B. Rajagopal, A. V. Sharma and M. V. Ramana, 2011a, "Electric and FTIR studies on magnesium hydrogen maleate hexahydrate (MHMH) single crystals", Scholars Research Library, Archives of Applied Science Research, 3 (3), pp 321-326.

8. B. Rajagopal, A. V. Sharma and M. V. Ramana, 2011b, "Growth and characterisation of Nickel doped Magnesium Hydrogen Maleate Hexahydrate single crystals", Scholars Research Library, Archives of Physics Research, 2011, 2(3), pp 180-185.

9. B. Rajagopal, M.V. Ramana and A.V. Sarma, 2011c, "Dielectric, Thermal and FTIR Studies of Cobalt Doped Magnesium Hydrogen Maleate Hexahydrate Single Crystals", Material Science Research India, Vol. 8(1), pp 91-96.

10. B. Rajagopal, A. V. Sharma and M. V. Ramana, 2011d, "Dielectric, Thermal and FTIR studies of Chromium doped Magnesium hydrogen maleate hexahydrate single crystals", Pelagia Research Library, Advances in Applied Science Research, 2 (4), pp 116-122. 
11. S. Suresh, A. Ramanand, and D. Jayaraman, 2011e, "Growth, optical, dielectric and fundamental properties of L-arginine acetate NLO single crystal", Recent Research in Science and Technology, 3(1): pp 25-28.

12. K. Rajarajan, S. Selvakumar, Ginson P. Joseph, M. Gulam Mohamed, I.Vedha Potheher and P. Sagayaraj, 2005, "Mechanical, dielectric and photoconducting properties of a novel non-linear optical crystal", Indian Journal of Pure \& Applied Physics, Vol 43, pp 926-930.

13. S. Tamilselvan, X. Helan Flora, A. Cyrac Peter, M. Gulam Mohamed,C.K. Mahadevan, M. Vimalan and J. Madhavan, 2011f, "Growth and electrical properties of NLO crystals of L-Asparaginium nitrate (LAsN)", Scholars Research Library: Archives of Applied Science Research, 3 (1): pp 235-240.

14. S. Suresh, A. Ramanand, D. Jayaraman, P. Mani and K. Anand, 2011g, "Growth, Optical, Theoretical and Dielectric Studies on L-Valine Single Crystal", International Journal of Chem Tech Research, 3, 1, pp 122-125.

15. Mohd Hamzah Harun, Elias Saion, Anuar Kassim, Muhd Yousuf Hussain, Iskandar Shahrim Mustafa and Muhd Ahmad Ali Omer, 2008, “Temperature Dependence of AC Electrical Conductivity of PVA Composite Polymer Film”, Malaysian Polymer Journal, Vol 3, No 2, pp 24-31.

16. T. Uma Devi, N. Lawrence, R. Rameshbabu, S. Selvanayagam, Helen Stoeckli Evans, G. Bhagavannarayana, K. Ramamurthi, 2010, "Synthesis, Crystal Growth, Structural, Optical, Thermal and Mechanical Properties of Semiorganic Nonlinear Optical Material, L-Cystine Dihydrochloride", J Minerals \& Materials Characterization \& Engineering, Vol 9, No 5, pp 495-507. 